\title{
Evolution of surgical therapy for Stanford acute type A aortic dissection
}

\author{
Peter Chiu, D. Craig Miller \\ Department of Cardiothoracic Surgery, Stanford University, School of Medicine, Stanford, CA, USA \\ Correspondence to: D. Craig Miller, MD. Department of Cardiothoracic Surgery, Falk CV Research Center, Stanford University, School of Medicine, \\ 300 Pasteur Drive, Stanford, CA94305, Stanford, CA 94305, USA. Email: dcm@stanford.edu.
}

\begin{abstract}
Acute type A aortic dissection (AcA-AoD) is a surgical emergency associated with very high morbidity and mortality. Unfortunately, the early outcome of emergency surgical repair has not improved substantially over the last 20 years. Many of the same debates occur repeatedly regarding operative extent and optimal conduct of the operation. The question remains: are patients suffering from too large an operation or too small? The pendulum favoring routine aortic valve resuspension, when feasible, has swung towards frequent aortic root replacement. This already aggressive approach is now being challenged with the even more extensive valve-sparing aortic root replacement (V-SARR) in selected patients. Distally, open replacement of most of the transverse arch is best in most patients. The need for late aortic re-intervention has not been shown to be affected by more extensive distal operative procedures, but the contemporary enthusiasm for a distal frozen elephant trunk (FET) only seems to build. It must be remembered that the first and foremost goal of the operation is to have an operative survivor; additional measures to reduce late morbidity are secondary aspirations. With increasing experience, true contraindications to emergency surgical operation have dwindled, but patients with advanced age, multiple comorbidities, and major neurological deficits do not fare well. The endovascular revolution, moreover, has spawned innovative options for modern practice, including ascending stent graft and adaptations of the old flap fenestration technique. Despite the increasingly complex operations and ever expanding therapies, this life-threatening disease remains a stubborn challenge for all cardiovascular surgeons. Development of specialized thoracic aortic teams and regionalization of care for patients with AcA-AoD offers the most promise to improve overall results.
\end{abstract}

Keywords: Aortic dissection; aortic root; aortic arch; history

Submitted Mar 31, 2016. Accepted for publication May 05, 2016.

doi: 10.21037 /acs.2016.05.05

View this article at: http://dx.doi.org/10.21037/acs.2016.05.05

\section{Introduction}

Aortic dissection is a catastrophic disease process, with an age-dependent incidence ranging from between 3.5 and $6 / 100,000$ person-years in the general population to as high as 10/100,000 person-years in the elderly (1-3). Early surgical treatment for patients with acute type A aortic dissection (AcA-AoD) was punctuated by mortality between $28 \%$ and $58 \%(4,5)$. Despite continuous advances in diagnostic methods, operative technique, and perioperative care, AcAAoD remains a major unsolved cardiovascular surgical challenge, as illustrated by the most recent International
Registry of Acute Aortic Dissection (IRAD) report showing an $18 \%$ operative mortality in a contemporary cohort [2010-2013] (6). The evolution of surgery for AcA-AoD has not been straightforward: recurring themes have arisen and faded repeatedly, and critical appraisal is warranted (Video 1).

\section{Terminology and classification}

\section{Stanford vs. DeBakey}

Simple anatomic features affect both the biological behavior of the dissection and the clinical management of patients 
with aortic dissection. Many classification systems have been promoted since the $1950 \mathrm{~s}$, but only two are used today: the Stanford and DeBakey nomenclatures. Initially proposed in 1970 by Daily et al., the Stanford classification differentiates among aortic dissections based on whether the ascending aorta is involved, regardless of the site of tear and irrespective of the distal extent of dissection. If the ascending aorta is involved, then the patient is classified as having a type A dissection; if the ascending aorta is not involved (including arch dissections), then the patient is classified as a type B dissection (4). This functional approach is both relevant and simple: type A dissection requires emergency surgical intervention through a sternotomy, whereas type B dissection is primarily managed with medical therapy unless it is complicated. The site of primary intimal tear (PIT) was not originally mentioned in the Stanford A/B system, but today is an additional important variable that affects management decisions. The DeBakey classification, which changed in 1982 to become more similar to the Stanford classification, is as follows: dissections not involving the ascending aorta are termed type III, those limited to the ascending aorta are DeBakey type II, and dissections involving the ascending, arch, and descending aorta, are classified as type I $(7,8)$. Dake et al. have recently proposed a simple and practical classification for the triage of patients with aortic dissection which highlights the anatomic and clinical features necessary to make treatment decisions using the mnemonic "DISSECT": Duration, Intimal tear (location), Size (maximum diameter), Segmental Extent (ascending, descending, etc.), Complications, and Thrombosis of the false lumen (9). This scheme is aimed at the initial communication between a physician at an outlying hospital and the surgeon at the thoracic aortic referral center.

\section{Chronicity}

In the original Stanford classification scheme proposed by Daily et al., patients presenting within two weeks of aortic dissection were arbitrarily labeled acute, and those presenting beyond two weeks were labeled chronic (4). The current practice is for patients with AcA-AoD to undergo emergent operative intervention; those with chronic type A aortic dissection may be observed for development of symptoms, aneurysmal dilatation, or aortic insufficiency. Distinguishing between acute and chronic dissection in the patient presenting with acute chest pain can sometimes be difficult, but transesophageal echocardiography (TEE) or fast, thin-slice, gated computed tomographic angiography (CTA) usually can clarify the situation. When the dissection acuity is in doubt, the symptomatic patient should initially be treated as if the dissection were acute until proven otherwise.

\section{Spectrum of disease}

The classic form of aortic dissection is defined as ingress of blood into the wall of the aorta with subsequent separation of the mural layers (10). As early as the 19th century, the importance of the intimal tear was recognized by Peacock who hypothesized that dissection was the result of disruption of the "internal coats of the vessel" (11). Included within the pathological spectrum of aortic dissection are limited intimal tear (LIT), intramural hematoma (IMH), and penetrating aortic ulcer (PAU). IMH is pathologically distinct from aortic dissection as it lacks an intimal defect and thus has no communication with the true aortic lumen but is still able to propagate longitudinally along the aortic wall. In patients with LIT, which we also call "intimal stretch marks" or "mushroom caps", the intima is torn, exposing the media without propagation of any hematoma in either direction or rupture (12). Erosion into the media may manifest as a PAU, which has a characteristic outpouching appearance (what the Japanese call "ulcer-like projection") on angiography or CTA $(12,13)$. All of these entities exist on a spectrum, e.g., PAU may evolve to include IMH, IMH may progress to a true dissection, a nonreentering false lumen in a classic dissection may thrombose and thereafter mimic IMH. The implications of these pathologic variants as they apply to the ascending aorta are largely academic, as each is typically treated similarly to classic dissection $(14,15)$. There may be geographic and ethnic distinctions in the behavior of IMH, however, as reports from Japan have shown a more benign natural history compared to aortic dissection $(16,17)$, and acute type A IMH has been documented to heal spontaneously in a subset of Korean patients (18).

\section{Evolution of surgical therapy}

\section{Natural history}

In the first half of the $20^{\text {th }}$ century, aortic dissection was most commonly a post-mortem diagnosis (10). The inability to accurately diagnose these patients presented only part of the problem as surgical therapy was untested, and early 
medical therapy-sedation and bedrest-was largely ineffectual. As a result, the natural history of acute aortic dissection, either type A or type B, was almost uniformly progressive and fatal. In Hirst's series of 505 cases gathered between 1933 and 1954, the mortality rates were $21 \%$ at 24 hours, $74 \%$ at 14 days, and $93 \%$ at one year (10). This echoed Austen et al.'s report of 50 patients treated with supportive care at the Massachusetts General Hospital (MGH): $55 \%$ mortality at 14 days and $86 \%$ mortality at one year (19). Without surgical correction, patients eventually succumbed to aortic insufficiency, aortic rupture, myocardial infarction from extension into a coronary artery, or malperfusion secondary to obstruction of a branch of the aorta supplying the brain, viscera, or limbs.

\section{Scylla and Charybdis: medical or surgical therapy?}

The earliest operation to address acute aortic dissection was pioneered by Gurin, who performed an iliac fenestration to decompress a non-reentering false lumen causing acute leg ischemia (20). Subsequent efforts to treat AcA-AoD were based on this concept of fenestration. In 1955, DeBakey created a reentry tear in the proximal descending thoracic aorta in order to decompress the false lumen in the ascending aorta and aortic arch with obliteration of the distal false passage through a posterolateral thoracotomy (21). Around the same time, Shaw and colleagues at the MGH performed a fenestration in the abdominal aorta in a patient with AcAAoD and evidence of lower extremity malperfusion (22). Operative mortality for fenestration at the MGH was up to $50 \%$ ( 9 of 18 ) with an additional $28 \%$ mortality by one year secondary to further dissection or aortic rupture $(19,23)$. Flap fenestration was soon recognized to be palliative as it failed to restore the mural integrity of the ascending aorta and arch (7); however, without cardiopulmonary bypass, interventions on the ascending aorta and arch required either complicated extra-anatomic bypasses or ineffective circumferential aortic wrapping $(24,25)$.

With the advent of extracorporeal circulation, surgeons were able to intervene directly on the ascending aorta. At the beginning, the most commonly performed operation for AcA-AoD was suture obliteration of the false lumen both proximally and distally, followed by primary re-anastomosis of the aorta; graft replacement was reserved for chronic dissections (7,23,25-28). By 1961, the group in Houston had amassed 72 operative cases of aortic dissection, and this had grown to 179 cases by 1965 . On the basis of this, DeBakey developed his three-type classification system (vide supra) that was used to guide the operative approach $(7,29)$. The overall results reported in 1965 included an operative mortality rate of $21 \%$, and operative mortality was only $12 \%$ in the most recent period [1961-1964]. Based on this report, operative intervention on aortic dissection became broadly accepted. Reading the fine print of DeBakey's experience, however, revealed that chronic dissections represented $68 \%$ of the series, and only $21 \%$ of the patients had dissections involving the ascending aorta. The results of ascending aortic procedures for acute and chronic dissection were more sobering with an overall $30 \%$ mortality rate; moreover, the mortality rate for AcA-AoD was 40\% (7).

Buoyed by DeBakey's favorable results, centers across the country began to attempt emergency surgical repair on patients with acute aortic dissections. The results were notably less successful, viz., Wheat et al. at the University of Florida operated on five patients with acute dissection and one with a chronic dissection between 1958 and 1963 with a mortality rate of $100 \%$ (30-33). Based on experimental data in rabbits and dogs in addition to observational studies in turkeys, Wheat and Palmer, a clinical pharmacologist, treated six consecutive patients with uncomplicated aortic dissection medically and all survived the acute phase, thus giving birth to medical therapy of aortic dissection (31). The long-term results of "impulse reduction" medical therapy, however, were modest: McFarland reported only a $52 \%$ survival rate (11/21) in patients with acute dissections, both type $\mathrm{A}$ and type $\mathrm{B}$, at a mean follow-up of 39 months (34). Thus, the cardiac surgeon was forced to navigate between the metaphorical Scylla and Charybdis: choosing between a very risky operation and medical therapy with uncertain long-term effectiveness.

\section{Type B or not type B? That is the question}

A critical refinement in the appropriate selection of patients for either operative intervention or intensive medical management was reported by Daily et al. in 1970, with the revelation that the optimal strategy varied based on whether the ascending aorta was involved. Whereas medical management was associated with $67 \%$ mortality in AcAAoD, the operative mortality rate was $28 \%$. For patients with acute type $\mathrm{B}$ aortic dissection, mortality was equivalent between surgical and medical treatment. On the basis of these results, the Stanford group recommended emergency operation through a sternotomy for patients with AcA-AoD and medical management of those with acute type $\mathrm{B}$ aortic dissection, unless complications arose (4). These results were paralleled at the Peter Bent Brigham Hospital and 
the University of Alabama emphasizing the importance of distinguishing between type $\mathrm{A}$ and type $\mathrm{B}$ dissections $(35,36)$. Rapid diagnosis and institution of appropriate therapy became key: should the patient be rushed to the operating room or go to the intensive care unit? A renaissance in diagnostic imaging greatly aided this dilemma.

In that era, only direct aortography was available to make the reliable ante mortem diagnosis of aortic dissection and determine whether the ascending aorta was involved; it rapidly became an obligatory element of the diagnostic workup of patients with suspected aortic dissection $(35,37,38)$. The early reliance on invasive, time-consuming, risky aortography was eventually replaced by less invasive, faster, and more convenient diagnostic imaging methods including the current main-stay, CTA (39-41). In these early days, the sensitivity and specificity of early computed tomography (CT) in detecting thoracic aortic dissection lagged behind that of other imaging modalities such as TEE and magnetic resonance imaging (MRI) (42). As noninvasive imaging methods improved, the folly of continued reliance on direct aortography became apparent. Not only did angiography carry intrinsic risk, but it also caused a substantial operative delay associated with an increase in mortality (43). In response to this, referral centers for thoracic aortic surgery developed integrated rapid diagnostic protocols for the evaluation of patients with suspected acute aortic dissection after direct transfer to the operating room or hybrid OR using TEE, Dyna CT, or occasionally angiography $(44,45)$.

At the end of the $20^{\text {th }}$ century, the initial imaging modality for patients diagnosed with AcA-AoD was CT in $46 \%$ and echocardiography (transthoracic or transesophageal) in $50 \%$, but there has been an increasing trend to use CTA (up to $73 \%$ between 2010 and 2013) as the initial diagnostic tool, with echocardiography representing $23 \%$ (6). The proliferation and refinement of CT technology has allowed for expeditious diagnosis locally followed by Air-Evac transfer to a thoracic aortic referral center where an experienced cardiovascular surgeon and multidisciplinary aortic team are available $(41,46)$. The preference at Stanford is for patients to be transferred directly to the operating room where they are anesthetized, and TEE is performed to confirm the presence of dissection involving the ascending aorta, map out the location of the PIT and major flap fenestrations, and evaluate downstream flow dynamics. This strategy avoids unnecessary preoperative delays along with preventing unnecessary operations for patients with a false positive finding on the initial CTA performed at the referring institution.

\section{Nihil sub sole novum: the cyclical debate on extent of operation}

In 1970, the Stanford group advocated for replacement of the ascending aorta rather than aortorrhaphy or fenestration, which were preferred by others, on the basis that graft replacement of the aorta would reduce the tension on friable aortic tissue in addition to guarding against repeat dissection and the development of late aortic insufficiency (4). Thereafter, replacement of the ascending aorta became the standard approach, but the proximal and distal extent of operation became-and continues to be-controversial. With advances in operative technique, cardiopulmonary bypass technology, and perioperative care, the technical feasibility of extensive aortic replacement has become less of an issue. What remains unknown is how to select precisely the patients who will benefit long-term from a more extensive initial operation.

\section{Replacement of the valve and root}

The approach to both the aortic valve and root has generally been conservative at Stanford. Indeed, the majority of patients at not only Stanford but also the Cleveland Clinic have had their aortic valve and root preserved using supracoronary aortic grafts, commissural resuspension, and a variety of sinus of Valsalva reparative techniques with a low rate of subsequent re-intervention for late aortic valve issues $(38,41,47-49)$. This conservative attitude towards the valve per se can be continued, even if root replacement is necessary. Tirone David re-implantation valve-sparing aortic root replacement (V-SARR) in carefully selected, younger AcA-AoD patients who are not moribund has been reported with acceptable mid-term results from Hannover, Germany and by Chen's group at Emory $(50,51)$.

If the valve cannot be conserved in a durable manner due to abnormal cusp pathology or dissection trauma, it should be replaced. Although bioprosthetic valves have proven to be reasonably durable when used in patients over 6570 years of age, younger patients undergoing aortic valve replacement (AVR) with a bioprosthesis [either separately or as part of a composite valve graft (CVG) root replacement] face a much higher risk of bioprosthetic structural valve deterioration (SVD) within 15 years, and this markedly tempers enthusiasm for this approach (52-54). Mechanical prosthetic AVR requires life-long anticoagulation with 
the attendant risk of bleeding and embolic complications. Among patients 50-69 years old, though, mechanical AVR has a much lower risk of reoperation and may in fact impart a survival benefit (55-57). Mechanical prostheses are recommended for AVR in patients younger than 60 unless there are contraindications to anticoagulation, while bioprosthetic valves are favored among patients older than 70 (58). For those aged $60-70$, individual judgment is necessary, with consideration of the patient's life expectancy and comorbidities. In AcA-AoD, we continue to believe that preservation of the aortic valve is preferable if the cusps are relatively normal, since the ideal prosthetic valve substitute does not exist. In addition to preoperative clinical status and direct inspection, intra-operative TEE is critical to determine which patients should have their valves and/or root preserved (59).

Techniques for extending the operation proximally have evolved over time. Early in the experience at Stanford, Teflon felt was used to fill the false lumen and reinforce the aorta externally $(41,48)$. Although Teflon felt is only very rarely used today at Stanford for any thoracic aortic procedure (instead we rely on fine suture with a small needle to reconstruct the dissected layers), this technique is used commonly elsewhere to avoid CVG replacement $(44,60,61)$. In Europe during the 1980s and 1990s, gelatin-resorcinolformaldehyde (GRF) "French" glue was popular for reconstructing the friable Sinus of Valsalva tissue. It reduced bleeding and facilitated sewing the proximal anastomosis with adequate mid-term outcomes (62-66). Subsequently, the occurrence of false aneurysms in glued aortic segments with pathological evidence of reactive fibrosis and tissue necrosis dampened enthusiasm for glue in aortic surgery, and this was especially the case with GRF French glue due to concerns about the toxicity of its formalin component (64,67-69). Despite newer formulations of biologic gluebovine serum albumin with glutaraldehyde (BioGlue, CryoLife Inc., Kennesaw, GA, USA)—having removed the formalin, concerns about tissue necrosis and the potential for false aneurysm formation still remain $(68,70,71)$. We do not routinely use biologic glue to reconstruct the aortic root or distal aorta. Patients in whom a more extensive and complex operation may not be tolerated-including those with major comorbidities, extremely advanced age, or critical preoperative condition-where there is severe dissection-induced damage to the aortic root may benefit from a smaller procedure facilitated by the use of biologic glue, provided that it is used very sparingly and carefully. This is a compromise, and these patients must undergo enhanced postoperative surveillance of the glued aortic segments.

Advocates for more extensive proximal work during the initial operation point to the potential need for late reoperation on the valve and root-with its attendant morbidity and mortality risk-if a conservative approach is used at the index operation. This has been a recurring theme undulating throughout the history of surgical repair of AcAAoD starting in the 1970s, with Kirklin recommending root replacement in all patients who required AVR $(36,72)$ and Cooley recommending AVR for all patients with aortic regurgitation $(73,74)$. This aggressive approach to the root was later advocated by Kouchoukos et al. and then Massimo et al. in the 1980s $(72,75)$, and it has since been revived again by Griepp's group at Mt. Sinai (76). The earlier practice at Stanford may have been overly conservative by saving the valve and sinuses in the vast majority of patients, but it appears to be the predominant treatment method in Japan where only $6.2 \%$ of AcA-AoD patients underwent root replacement in 2011 (77).

Performing root replacement using a CVG prolongs the cardiopulmonary bypass and aortic cross clamp times $(78,79)$; it also increases the complexity of the operation. In the hands of expert thoracic aortic surgeons, the mortality risk may not be substantially elevated $(76,78,80)$; however, the apparent safety of CVG root replacement may be due in part to publication bias as low risk has not been universally observed even among experienced surgeons $(61,81)$. It is important to recall that the median number of proximal aortic operations among institutions performing at least one aortic operation per year in the Society of Thoracic Surgeons (STS) Adult Cardiac Surgery Database (ACSD) is only 12 per year per center (82). Mortality is higher in the elective setting among institutions performing fewer than 30 aortic root replacements or separate valve graft procedures annually (83). Another report from the STS database spanning 2004-2010 including 13,743 patients by Stamou et al. revealed eye-opening numbers: the median annual number of aortic root replacement procedures (excluding acute dissection and endocarditis) was only two cases in 2009 , and only $5 \%$ of centers performed $>16$ aortic root replacement operations per year (84). As such, it may not be prudent to recommend universal replacement of the aortic root in patients with AcA-AoD. This is especially the case given that the need for late proximal aortic reintervention may not actually be any lower than after ascending repair with valve resuspension (with or without root repair) $(49,76,78,85)$. Patients with the Marfan 

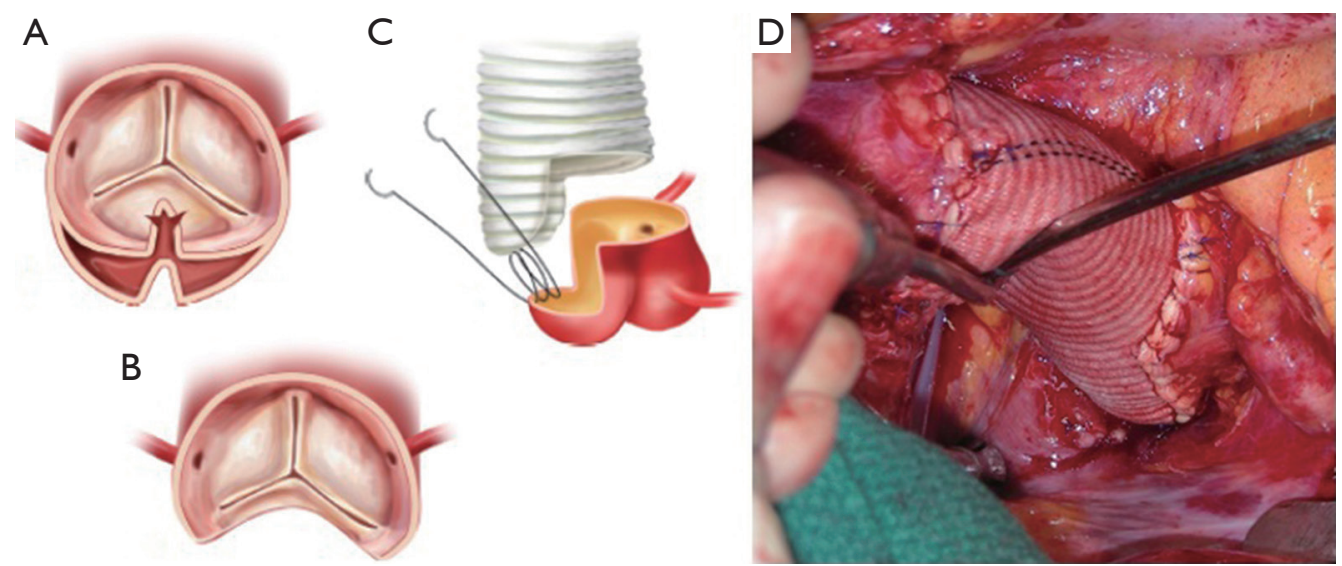

Figure 1 Limited aortic root remodeling operation known informally as a "uni-Yacoub" both at Stanford and in Leipzig: (A) extension of the primary intimal tear into the non-coronary sinus with extensive destruction of the wall; (B) resection of the entire primary intimal tear leaving an adequate rim of tissue for the remodeling procedure; (C) a custom tailored graft with a single tongue; (D) intraoperative photograph demonstrating the completed uni-Yacoub remodeling technique.

syndrome (MFS) or other connective tissue disorders are an exception, as $40 \%$ of patients with MFS undergoing supracoronary graft replacement for AcA-AoD require another root operation at 10 years (86). MFS patients-and those patients with preexisting root aneurysms or extensively dissected aortic roots-should all undergo CVG aortic root replacement or a V-SARR.

The valve is frequently normal in patients with AcA-AoD and thus potentially salvageable in spite of an extensively dissected aortic root and the presence of aortic regurgitation $(48,60)$. V-SARR, pioneered by David et al. $(87,88)$ and Sir Yacoub et al. (89), has been shown to have satisfactory 15 -year results in a variety of settings, including patients with connective tissue disorders and bicuspid aortopathy, in the proper experienced hands (90-94). V-SARR has proven to be a viable alternative to CVG among Marfan patients in the Aortic Valve Operative Outcomes in Marfan Patients (AVOOMP) multi-institutional registry, though V-SARR was less commonly performed in urgent or emergent situations (95). As these techniques apply to AcA-AoD, the Yacoub remodeling technique (also known as the David II or III V-SARR) (96), has been associated with an unacceptably high risk of both late reoperation and recurrent aortic regurgitation compared with the David reimplantation technique of V-SARR, i.e., David I, IV or V (97). The Leipzig group found that a limited root remodeling operation replacing one or two sinuses of Valsalva with tongues of Dacron graft-informally known as a "uniYacoub" or "bi-Yacoub" at both Stanford and Leipzig- produced results comparable to the David re-implantation in selected patients (98). The good results reported by Leshnower and Chen et al. from Emory using the David V V-SARR technique selectively in $12 \%$ of their AcA-AoD series with only $4.7 \%$ operative mortality rate suggests that V-SARR may be a viable option in experienced hands for a subgroup of carefully selected, generally young patients who will derive the greatest benefit and will be able to tolerate the bigger operation (51). Similar results have been reported from Hannover, Germany (50). Okita's group in Kobe, Japan had equivalent perioperative results $(5 \%$ mortality rate amongst 21 patients), but AcA-AoD was a significant risk factor for both recurrent aortic regurgitation and reoperation in their overall experience with V-SARR (99).

In patients where the probability of durable valve salvage is high, our preference is to perform supra-coronary replacement of the ascending aorta with resuspension of the valve. In selected patients with extensive destruction of the non-coronary sinus and in some cases the right sinus, a limited aortic root remodeling operation ( "uni-Yacoub" or "bi-Yacoub") is appropriate (Figure $1 A-D$ ); in the case of the right sinus, the right coronary artery is reimplanted as a Carrel patch into the Dacron tongue. On the other hand, when there exists a high probability of requiring subsequent re-intervention (patients with pre-existing aortic root pathology, extensive aortic root dissection, or connective tissue disorder), a more aggressive approach is warranted. Our preference in this group of patients is to perform root replacement with a CVG using full thickness Carrel 

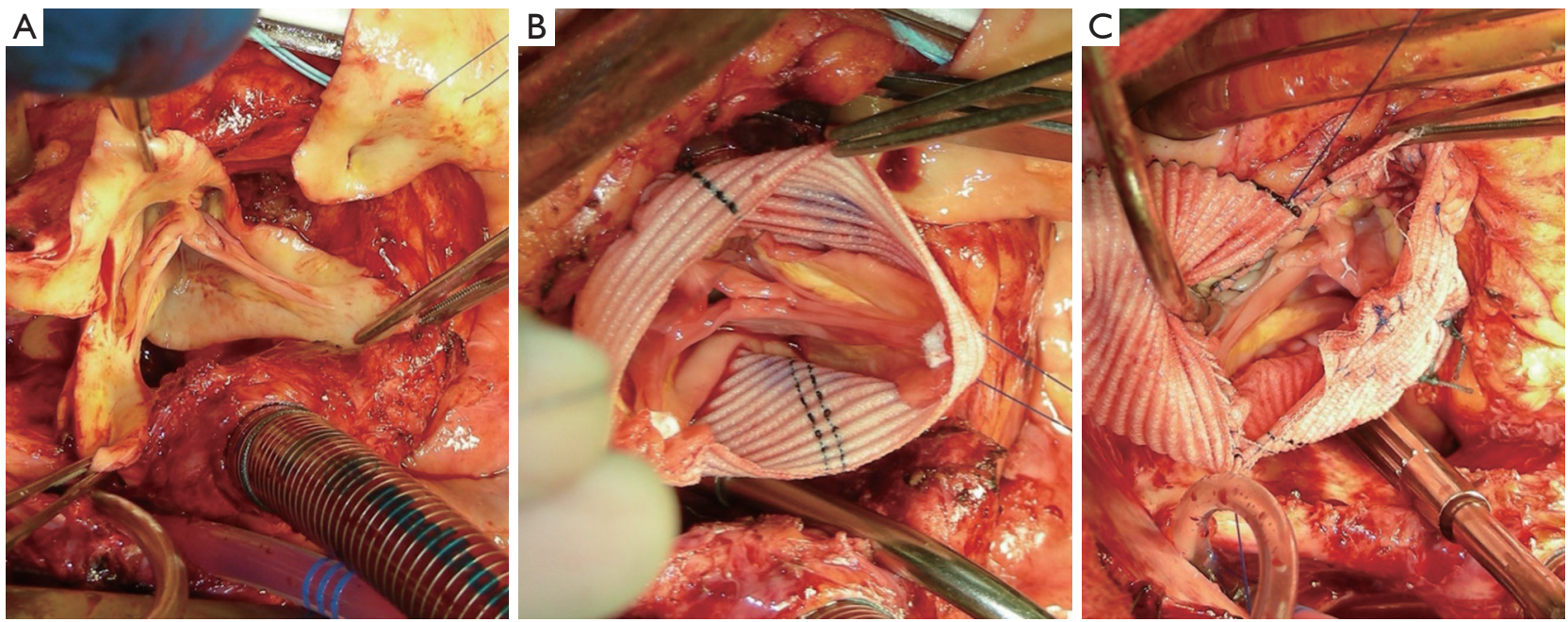

Figure 2 Intraoperative photograph of the Tirone David V re-implantation technique for valve sparing aortic root replacement: (A) sinuses are excised leaving a rim of aortic tissue around the valve itself; (B) the root graft is over-sized and then "necked down" to appropriate annular dimensions using the Feindel-David equation, and the commissures are positioned to optimize cusp coaptation (not seen: 12 interrupted sub-annular horizontal mattress sutures are placed to anchor the graft); (C) graft-to-graft anastomosis after re-implantation of the coronary ostia as carrel patches.

patches for coronary re-implantation to avoid formation of either pseudoaneurysms or a pressurized aneurysm sac, both of which plagued the classical "wrap inclusion" Bentall procedure (100). In redo operations or in patients with existing aneurysmal disease and grossly displaced coronary ostia, it may not be possible to mobilize fully the coronary ostia for direct reimplantation without undue tension. A variety of ingenious techniques have been developed to address this problem, the most common of which are the Cabrol moustache graft (100) and the KayZubiate end-to-end saphenous vein graft extension (101). Given the late coronary graft occlusions (particularly the right coronary artery) seen after the Cabrol moustache technique $(102,103)$, we avoid it whenever possible. Complete dissection of the root and extensive mobilization of the coronary ostia usually allows for reimplantation of one of the two ostia directly into the graft, allowing for a single 8 or $10 \mathrm{~mm}$ Dacron or saphenous vein interposition graft for the remaining coronary. Care must be taken to expose enough epicardium to create a sound and hemostatic end-to-end anastomosis with the interposition graft. Given the added technical complexity of the David reimplantation technique, V-SARR should be performed by experienced surgeons and reserved for highly selected young patients who are not moribund preoperatively, have normal appearing cusps, and either existing aortic root disease or connective tissue disease (Figure $2 A-C$ ). The cardiac surgeon approaching a patient with an AcA-AoD is faced with a variety of potential hazards. Sound judgment is key: the primary goal is to have an operative survivor.

\section{The arch, cerebral protection and cannulation strategy}

The PIT is located in the arch in $10-30 \%$ of patients $(10,65,80,104,105)$. Without adequate cerebral protection, however, arch procedures historically were fraught with danger (mortality rates have been as high as $42 \%)(24,106)$. Thus, early efforts to resect a PIT in the arch or repair a ruptured arch were limited. Using profound hypothermic circulatory arrest (PHCA) and surface cooling in addition to cardiopulmonary bypass, Griepp and colleagues at Stanford successfully performed total arch replacements in 4 patients with arch aneurysms in the early 1970s (107). This technique of establishing a bloodless field was shown to be particularly useful in aortic dissections by Cooley, who was among the first to recommend the routine performance of an open distal anastomosis (ODA). The better visibility achieved by performing the distal anastomosis with PHCA allowed surgeons to evaluate the arch intima, ensure continuity with the true lumen, and obliterate the false lumen $(108,109)$. Performing the distal aortic anastomosis with the aorta clamped avoids profound hypothermia and 


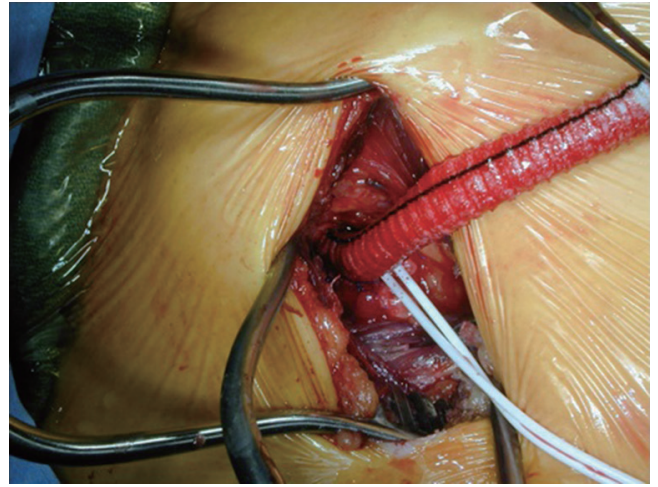

Figure 3 An 8-mm knitted double velour Dacron graft is used as an axillary perfusion limb for cardiopulmonary bypass and subsequent institution of selective antegrade cerebral perfusion with clamping of the innominate artery.

circulatory arrest. It also takes less time. However, the technical integrity and soundness of the anastomosis is compromised. This in turn increases the risk of anastomotic bleeding, graft dehiscence, and late false aneurysm formation requiring reoperation (110-112). Conversely, PHCA with ODA to date has not been definitively linked with lower operative mortality risk $(110,113)$.

With increasing global experience with PHCA, surgeons at Hôpital Fôch in Paris, Stanford, and Baylor began to report results of extending the operation for AcA-AoD into the arch in the late 1980s and early 1990s $(105,114,115)$. The additional morbidity and mortality associated with this more extensive approach limited widespread adoption and spawned the development of new methods of cerebral protection. Antegrade and retrograde cerebral perfusion (RCP) were developed as competing methods to improve cerebral protection.

Kazui used selective antegrade cerebral perfusion (SACP) at $10 \mathrm{~mL} / \mathrm{kg} / \mathrm{min}$ during PHCA and demonstrated no excess neurological morbidity or mortality among patients undergoing total aortic arch replacement compared with PHCA alone and suggested that this technique allowed for longer periods of safe circulatory arrest $(116,117)$. This technique gained popularity with the development of axillary artery cannulation first described by Sabik, using direct cannulation, and then Baribeau, with a small caliber graft, for SACP $(118,119)$. In spite of the additional time required to dissect out the axillary artery and sew a perfusion graft to it, this technique has been used successfully worldwide in the emergency setting of AcAAoD $(120,121)$.
Ueda et al. pioneered the use of RCP for neuroprotection demonstrating safe and effective repair of the arch without clamping the head vessels (122). The simplicity of the technique, which did not require substantial alteration of cannulation strategy, allowed for rapid setup in both elective and emergency situations $(60,123,124)$. The presence of a competent internal jugular vein valve and extensive venovenous shunting, however, severely limit the effectiveness of this technique, as only a fraction of the blood delivered into the superior vena cava for RCP actually reaches the brain $(125,126)$. Griepp's group showed in animal models that RCP (with the azygos vein ligated) carried a risk of cerebral edema and had minimal delivery of blood to the capillaries of the brain; however, it was effective as a means of clearing particulate emboli when inferior vena cava occlusion was additionally employed $(127,128)$.

In an effort to determine the optimal means of neuroprotection, Svensson et al. recently reported a randomized trial comparing intermittent antegrade brain perfusion with RCP in patients undergoing elective arch operations. They could not demonstrate any statistically significant difference between the two strategies. This trial was-in some respects-handicapped by the short period of circulatory arrest $(27 \pm 13$ minutes $)$, such that the magnitude of the cerebral insult was likely not great enough to discern any difference between brain protection methods (129). Reflecting the importance of time, the practice at the University of Pennsylvania has been to use RCP in general but to use bilateral antegrade perfusion in cases necessitating greater than 40 minutes of circulatory arrest (60).

We use unilateral SACP-right axillary artery perfusion with clamping of the innominate, left common carotid, and left subclavian arteries (Figure 3)-at $10 \mathrm{~mL} / \mathrm{kg} / \mathrm{min}$ and reserve bilateral carotid perfusion for situations in which the cerebral near-infrared spectroscopy (NIR) monitoring or tympanic membrane (TM) temperatures diverge and there is little back-bleeding from the left common carotid artery. In general, moderate systemic hypothermia (TM $\sim 20-22^{\circ} \mathrm{C}$, bladder temperature in $26-28{ }^{\circ} \mathrm{C}$ range) is appropriate for patients with AcA-AoD and other typical ascending and arch procedures. In more complex circumstances, e.g., redo total arch replacement with a multi-branch graft and a distal elephant trunk graft for chronic type A dissection, we employ SACP with the TM at $20^{\circ} \mathrm{C}$. and bladder temperatures in the $20-24^{\circ} \mathrm{C}$ range.

Related to safe brain protection is the arterial cannulation and perfusion strategy. Femoral arterial cannulation 
was historically the most commonly utilized technique $(38,41,105,110,114,130)$. Its use has waned markedly, but it continues to be used by some who favor PHCA alone for elective and emergent arch operations including Elefteriades' group $(131,132)$. One of the major benefits of femoral cannulation is its rapidity and simplicity. Conducting PHCA then requires no additional manipulation; if adjunctive RCP is deemed necessary, only cannulation of the superior vena cava and minor modification of the cardiopulmonary bypass circuit is necessary $(122,133)$. If femoral perfusion is used, only the artery with the absent or diminished pulse should be cannulated since it is most likely to connect to the proximal aortic true lumen. The safety of femoral cannulation in general has been questioned, though, given concerns about pressurization of the false lumen and malperfusion, which could be compounded when the distal ascending aorta is cross-clamped $(104,110,134)$. Evaluation of the risk associated with cross-clamping the aorta during the cooling phase and prior to PHCA have provided divergent results: some studies have reported increased risk $(110,121,135)$, and others have failed to show excess morbidity or mortality $(130,136)$.

With mounting evidence that retrograde perfusion via the femoral artery may be associated with worse clinical outcome in both elective and emergent settings $(120,124,137)$, we reserve femoral cannulation for patients with severe hemodynamic compromise, preoperative cardiac arrest, or extensive dissection of the axillary vessels. Alternatively, the true lumen in the arch may be cannulated directly using a guidewire and either TEE or epiaortic ultrasound for guidance as popularized by the group in Hannover and others (138-140). Another alternative approach is LV trans-apical (TA) cannulation across the aortic valve with TEE guidance, as first described in humans by Trinkle in 1970 with broad application by Wada and Kazui et al. (141-143). In these cases, reinstitution of cardiopulmonary bypass via direct cannulation of the arch graft after circulatory arrest is always done for antegrade body perfusion. During the re-warming and reperfusion time after PHCA, it is paramount to inspect the true lumen and dissection flap in the descending aorta using TEE to make sure that the true lumen is not obliterated, the distal elephant trunk (if a total arch has been performed) is correctly placed in the true lumen, there are no new tears in the dissection flap, and there is adequate distal perfusion via the true and/or false lumens. An important drawback to central aortic true lumen or LV TA cannulation is that SACP cannot be instantly started when systemic flow is turned off, as it can when using axillary artery perfusion.

\section{The fate of the dissected arch and thoracoabdominal aorta: how much distal operation is enough? How much is too much?}

The development of techniques for cerebral protection facilitated efforts to perform more extensive operations in the arch safely. In 1994, Ando et al. and Kazui et al. separately recommended more extensive distal repair in patients with AcA-AoD on the basis of low operative mortality in patients undergoing total arch replacement with SACP $(144,145)$. Follow-up by Kazui in 2000 reported a $16 \%$ mortality rate among 70 selected patients who underwent total arch replacement for AcA-AoD primarily using the multibranch technique, thus demonstrating the feasibility of emergent total arch replacement. They further suggested that the need for distal reoperation might be lower, but this aspiration was not borne out as the freedom from reoperation at 5 years was $77 \%$ (146).

In the early experience at Stanford and Washington University, the freedom from reoperation was not significantly different between patients who had undergone arch repair and those who had not $(80,115)$, but these studies were under-powered with respect to the need for late aortic reoperation. The Cleveland Clinic and more recently Gleason's team at the University of Pittsburgh have reported that a more extensive operation, i.e., total arch replacement, was associated with a trend towards lower early and late survival, though the differences were not statistically significant $(81,147)$. Finally, total arch replacement has not been shown to improve the freedom from late distal aortic reintervention compared with more conservative arch management in propensity score analyses from South Korea and Italy $(148,149)$.

This debate has fueled competing hypotheses about the optimal treatment of the arch in the context of AcA-AoD. It is logical to reserve total arch replacement for patients with the highest theoretical benefit, e.g., younger patients and those with MFS or other connective tissue disorder that theoretically puts them at higher risk of developing distal aortic complications; however, we still do not know with certainty which specific patient subsets are at highest risk. Nevertheless, despite the absence of rigorous data upon which to make this decision, many surgeons today have taken the ability to do a total arch replacement coupled with a distal frozen elephant trunk (FET) graft as evidence that it should be done often. The hope is that this may either reduce late re-intervention or create a sound foundation for subsequent down-stream stent-grafting if necessary. 
The absence of strong evidence supporting this approach highlights the compelling need for a proper prospective randomized controlled trial to address this major void in our knowledge base.

First described by Kato et al. in 1996, the FET technique has been used to deliver and secure a stent-graft farther distally than is possible with a conventional Borst elephant trunk graft (150). This technique has been associated with a high proportion of false lumen thrombosis in the descending thoracic aorta (but not the abdominal aorta) and low incidence of reoperation (0-6\%) in some reports (151-154). Elsewhere in the literature, though, re-intervention rates up to $25 \%$ have been reported; whether the rate of distal aortic re-intervention truly differs between those treated with a FET versus patients treated with more conventional techniques remains unknown leaving in question the true benefit of increased remodeling of the aorta $(153,155,156)$. Newer, more sophisticated composite devices such as the Terumo Vascutek Thoraflex Hybrid ${ }^{\circledR}$ multi-branch graft (Vascutek Ltd., Renfrewshire, Scotland) and the Jotec E-vita Open ${ }^{\circledR}$ system (Jotec GmbH, Hechingen, Germany), facilitate total arch replacement with FET and may make these operations safer, but further trials must be performed. The Thoraflex Hybrid ${ }^{\circledR}$ trial is starting in the US in 2016.

Our current procedure of choice is an aggressive peninsula-style transverse arch replacement in all patients with AcA-AoD where the dissection extends into the arch using unilateral SACP via axillary perfusion and moderate systemic hypothermia (vide supra) (157). This is particularly important among patients in whom the PIT or large re-entry tears are found in the arch, but also applies to patients with extensive dissection of the arch. A sound and hemostatic distal reconstruction can be achieved using fine-4-0 BB or 5-0 C-1 Prolene ${ }^{\circledast}$ (Ethicon, Somerville, NJ, USA)—suture on small needles in a relatively bloodless field avoiding both Teflonfelt reinforcement and bio-glue. Our goal is to excise as much of the dissected aortic tissue as possible without extending PHCA and cardiopulmonary bypass times excessively. With a single long suture line extending from near the ligamentum arteriosum in the distal arch to the innominate artery takeoff on the greater curve, the peninsula technique is safe and expedient (Figure 4A-E). In cases of arch rupture, severely traumatized arch due to the dissection, multiple arch tears, large arch aneurysm, or selected stable young patients with a heritable connective tissue disorder, total arch replacement utilizing the Kazui multi-branch technique with either a surgical elephant trunk graft (Figure $5 A, B$ ) or an antegrade Gore c-TAG ${ }^{\circledR}$ stent-graft (W.L. Gore, Flagstaff, AZ, USA) is a good option (Figure $6 A, B$ ). In deciding which patients should undergo a more extensive operation either proximally in the root or distally beyond the arch, it is critical to remember that the primary goal in a patient with an AcAAoD is to have a survivor. Concerns about reoperation on the downstream aorta should be secondary.

\section{Surveillance}

Since almost all patients have some degree of distal false lumen patency and residual dissection, ongoing aortic surveillance is imperative on a serial basis. We perform a new CTA at discharge followed by scans at 3, 6, 9, and then 12 months; thereafter, an annual CTA is obligatory on an indefinite basis in addition to regular echocardiographic follow-up to assess the aortic valve. If progressive aneurysmal dilatation of the residual dissected aorta (usually the false lumen) or aortic regurgitation is detected, timely referral to a center with special expertise in thoracic aortic disease is important so that elective reoperation or TEVAR can be considered prior to a catastrophic event. The actuarial estimate of freedom from reoperation at 5 years ranges from $77-95 \%(47,146,158)$. The need for ongoing follow up cannot be over-stated.

\section{Evolution of patient selection}

Over the past five decades, surgical limits have been pushed continuously not only in terms of the extent of operation performed but also with respect to patient selection. The proportion of patients treated non-operatively has declined in the last 20 years from $20 \%$ to $8 \%$ in the IRAD database, though it has remained around $15 \%$ at Duke $(6,159)$. These figures probably are underestimates given that these are all tertiary referral centers and therefore do not capture patients who either did not survive transfer or were not offered transfer from outlying hospitals. As usual, we surgeons are living in the "numerator" without knowing the real denominator.

\section{Malperfusion}

Propagation of the dissection flap into the arch and beyond leads to aortic branch compromise in approximately $30 \%$ of patients with subsequent malperfusion of the brain, limbs, or viscera and portends markedly worse outcomes (160-163). Cerebral malperfusion and neurological injury, manifesting as stroke or coma, affect $5-15 \%$ of patients with AcA-AoD 
A

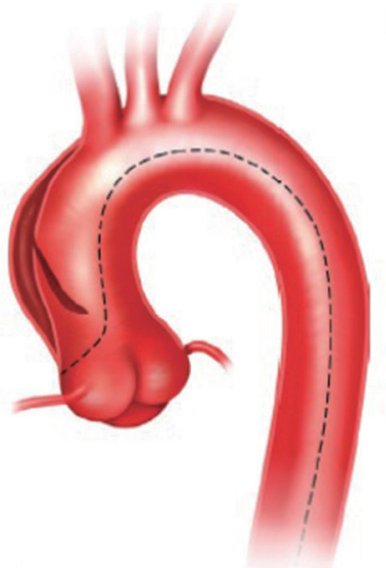

B

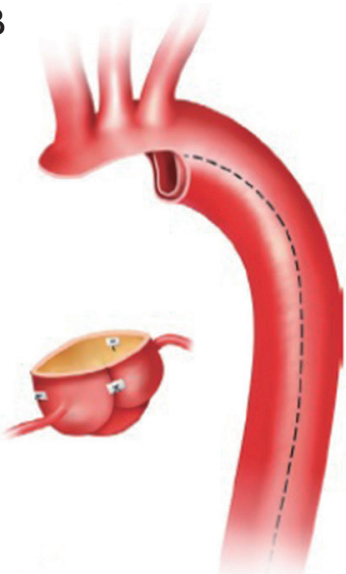

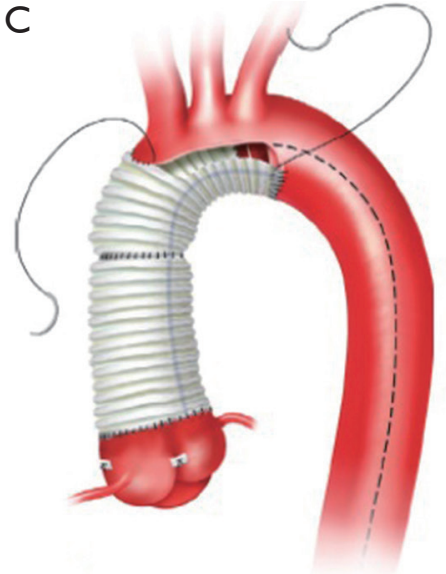

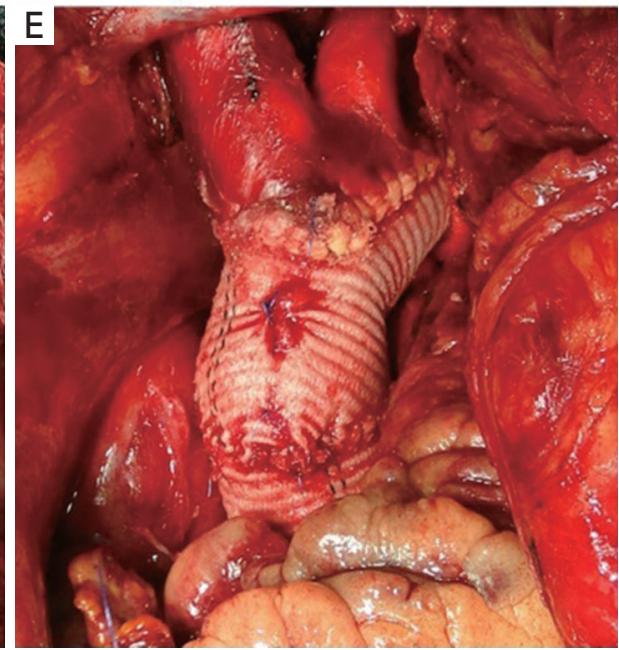

Figure 4 Peninsula-style transverse arch repair is our favored approach to the distal extent of operation: (A) artist's rendition of an acute type A aortic dissection-dashed-line indicates dissection; (B) after excising the entire underside of the aortic arch, the head vessels are attached to the remainder of the aorta by a thin peninsula of tissue; (C) the graft is tailored to match the aorta, and a running suture on a fine needle is used to construct the distal anastomosis; (D) intraoperative photograph demonstrating the configuration of the distal anastomosis; (E) intraoperative photograph of completed peninsula-style transverse arch repair.

(164-167). Though long considered to be a contraindication given the risks associated with heparinization and cardiopulmonary bypass $(161,168)$, cerebral injury-short of brain death-has not routinely been used as an exclusion criterion for operative intervention for patients with AcAAoD at Stanford $(164,169)$. Addressing the ascending aorta and reconstituting true lumen flow distally often results in resolution of the cerebral deficit, but this depends on the extent of neurological injury and timing of operation. Patients undergoing operative repair within 5-8 hours of symptom onset have a substantially better prognosis with a large proportion experiencing complete resolution of neurological deficits as compared to those with a longer duration of symptoms $(162,165,166)$. In neurologically devastated patients presenting longer after the onset of symptoms, there is no benefit of surgical intervention. Rapid diagnosis and institution of appropriate treatment is absolutely critical as even comatose patients may be salvageable if the operation is not delayed.

Due to the poor outcomes associated with malperfusion, Deeb and colleagues at the University of Michigan began to manage patients medically and correct malperfusion with catheter-based techniques-including flap fenestration (not unlike the MGH group 40 years previously) and true lumen stenting-prior to proceeding with definitive aortic repair at a later date. Compared with an $89 \%$ historical mortality 

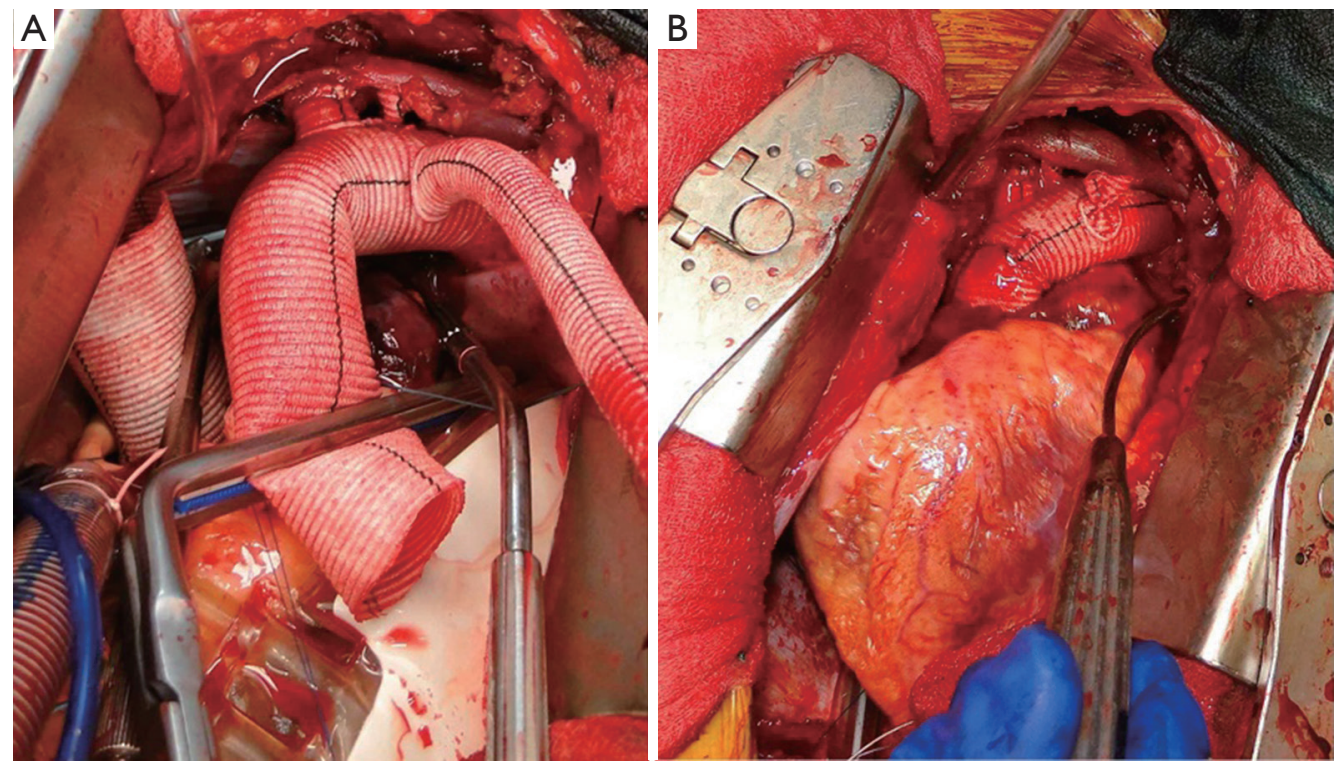

Figure 5 Intraoperative photographs of multibranch total arch replacement: (A) following completion of multibranch reconstruction with perfusion via side arm graft; (B) completed total arch reconstruction following completion of the graft-to-graft anastomosis and ligation of the side arm graft.

\section{A}

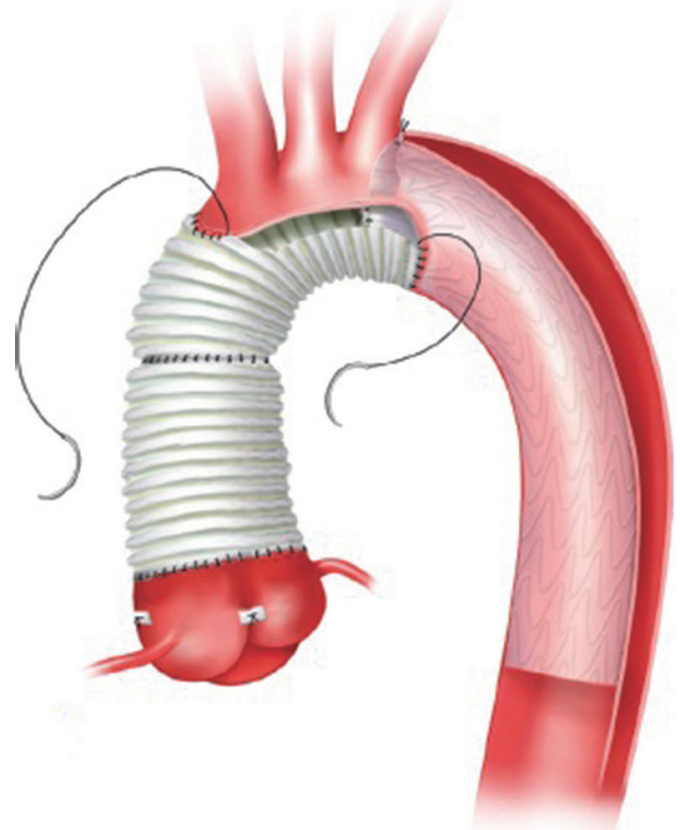

B

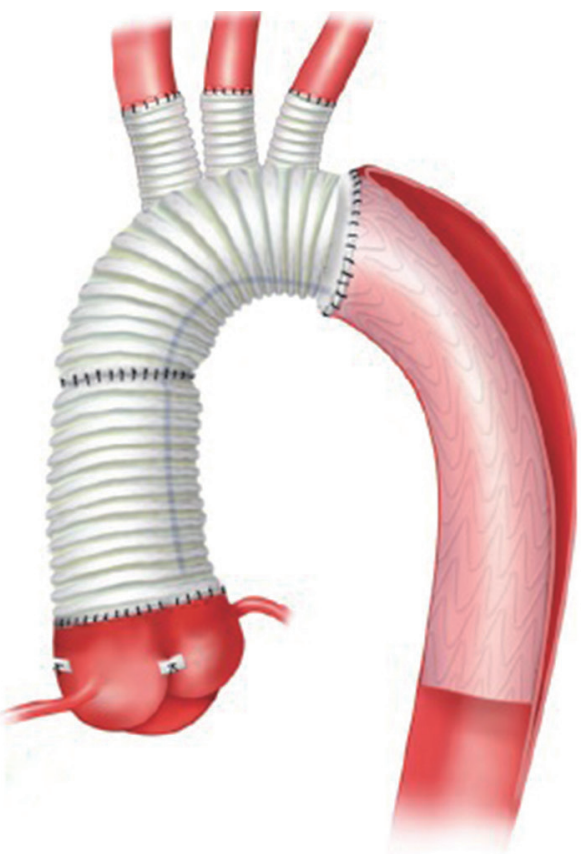

Figure 6 Frozen elephant trunk technique: (A) in conjunction with a peninsula-style transverse arch repair; (B) in conjunction with a multibranch total arch replacement. 
rate among patients undergoing immediate ascending aortic operation, the mortality rate associated with their strategy of delaying the ascending aortic procedure between 2 and 67 days was $25 \%$ (5/20), including three patients dying before the definitive operation could be carried out (170). In a later report, mortality awaiting operation was 33\% (23/70); however, if the patient eventually received ascending aortic repair, the operative mortality risk was equivalent to the uncomplicated patients who underwent early aortic repair (163). The Michigan strategy offers rapid correction of peripheral malperfusion without the operative insult of a definitive ascending aortic and arch operation; it also allows patients with advanced peripheral ischemia/infarction precluding survival to declare themselves, which eliminates the need for a futile ascending aortic procedure. We do not subscribe to this policy as a general rule since the death rate while waiting for definitive aortic repair is excessively high. Despite $95 \%$ technical success, one-half of the mortality seen in the group awaiting repair was due to malperfusion complications (11 of 23) and the other half due to rupture (12 of 23). The former may not have been suitable candidates for ascending repair at all, but the latter may have been salvageable with an expedient aortic operation. It still remains unclear exactly which individual patients stand to benefit from a preliminary endovascular intervention.

\section{Elderly patients}

Advanced age has been shown to be a consistent predictor of higher operative mortality in patients with AcA-AoD $(47,60,85,171)$. Neri et al. from Siena, Italy reported an operative mortality rate of $83 \%$ in octogenarians with complicated dissections with little meaningful functional rehabilitation thereafter in the few survivors. On account of this, they deemed operative intervention to be futile for these patients; the authors claimed they felt compelled to offer these very sick patients an operation due to ethical, social, and cultural considerations in Italy (172). An ethical controversy may thus arise as a result of the conflict between families who want to pursue "everything possible" and the surgical team who would like to avoid the torture of futile care. McKneally has recommended the establishment of local policies, rather than professional guidelines, in concert with the general public as a means of determining a socially acceptable approach to a complex and nuanced situation. "We don't do that here" would then be a phrase that carries the weight of the community and, as McKneally suggests, may be an effective means of resolving conflicts that arise (173). With increasing experience and improving technology, the operative mortality rate among this older population has declined to $13-25 \%$ in more recent reports $(171,174)$. Despite declining perioperative mortality, Hata et al. reported that $17 \%$ of surviving octogenarians were bedridden and $46 \%$ were demented. This is certainly not a good outcome and begs the question: Why were these patients offered an emergency operation at all? The tendency to avoid aggressive therapy in the very elderly is reflected in IRAD by a substantial increase in the fraction of patients older than 80 treated medically; indeed, there was no difference in outcome between medically and surgically treated octogenarians (175). The decision to operate must be made in concert with the family, including a frank discussion of all risks, the option of withholding heroic treatment, and complete understanding of their expectations. The patient and family must accept that even if the patient survives his or her postoperative quality of life may be substantially compromised. With an aging population, this clinical conundrum will occur with increasing frequency. The heterogeneity of this group, however, precludes the use of any blanket guideline; seasoned surgical judgment is key and must be exercised.

\section{Medical management}

Every patient is initially managed medically once the diagnosis of AcA-AoD is suspected and while en route to the operating room. Among the $10-15 \%$ of patients who are treated non-operatively, the principle of "impulse reduction" (lower aortic $\mathrm{dP} / \mathrm{dt}$, i.e., change in aortic pressure over change in time) put forward by Wheat and Palmer more than 50 years ago is still employed. Beta blockers are the drugs of choice; arteriolar dilating antihypertensive medications should be avoided unless the patient is adequately betablocked.

Mortality associated with medical management in AcA-AoD ranged from 49\% to 64\% between 1995 and 2013 without any evident change over time in the IRAD database (6). This may be an improvement on Hirst's observed mortality among undifferentiated type A and type $B$ aortic dissections from the first half of the $20^{\text {th }}$ century, but it still serves as a somber reminder that AcA-AoD is first and foremost a surgical disease in suitable candidates.

\section{Ascending aortic stent-graft}

Among patients deemed inoperable by a cardiovascular 
surgeon, ascending aortic stent-grafting has been tried as a heroic salvage measure in a small number of patients utilizing transfemoral, transcarotid, TA, and transaxillary access; surprisingly the mortality rate was not prohibitively high $(176,177)$. This work remains highly investigational, but the TA approach is probably safest at the moment due to the shorter working distance and finer control of device positioning. Currently there is no standardized strategy. With technological improvements, these endovascular methods might be effective in patients who otherwise are doomed. These investigational therapies should only be explored in referral centers where there are cardiovascular surgeons with experience in both open and endovascular repair and multi-disciplinary thoracic aortic treatment teams.

\section{Importance of thoracic aortic referral centers}

Increasing regionalization of care for patients with thoracic aortic diseases, including AcA-AoD, in tertiary referral centers has become an important element of modern thoracic aortic surgery. Multi-disciplinary teams (cardiac anesthesia, cardiology, interventional radiology, cardiovascular critical care, and cardiovascular surgery) with broad expertise and experience can provide more effective care for these challenging patients. A relationship between volume of aortic dissection cases and outcome in the Nationwide Inpatient Sample (NIS) has been reported despite the relatively modest number of operations annually that made an institution a "high volume" center [in separate analyses, $>2.5$ cases (178) and >13 cases (179) per hospital annually], but volume of thoracic aortic operations may be more important than volume of AcA-AoD (159). Higher annual case volume is likely a proxy for a multiplicity of factors: availability of consultative services, cardiac anesthesiologist familiarity with aortic operations, intensive care unit resources, and surgeon experience.

Though only part of the overall picture, a survey of Canadian surgeons demonstrated that increasing surgeon experience was associated with differences in management both inside the operating room and afterwards. Surgeons with higher overall case and aortic dissection volume were more likely to use SACP for neuroprotection as well as warmer target hypothermic systemic temperatures (180). Preferred operative management and postoperative care still varied substantially between surgeons despite the limited number of cardiac surgery centers in Canada, approximately one per million population, meaning there were few low volume cardiac surgery centers.

By incorporating both technical modifications and process improvements, the Duke Thoracic Aortic Surgery Program was able to reduce their operative mortality rate in patients with AcA-AoD from 33.9\% to an impressive $2.8 \%$ in two consecutive 6-year intervals. After institution of the Thoracic Aortic Surgery Program, use of right axillary perfusion for SACP during PHCA became the norm, and performance of an ODA became routine $(25 \%$ before and $94 \%$ after). Process changes included early use of low-dose recombinant Factor VII to reduce bleeding complications and avoiding off-shift nocturnal emergency operations in stable patients $>48$ hours from the onset of symptoms. The success seen at Duke underlines the importance of regionalization of care for patients with AcAAoD and limiting AcA-AoD cases to a small, dedicated, and coordinated multi-disciplinary thoracic aortic team that not only sees enough cases monthly to keep their skills up but also takes an integrated approach to the management of these patients (159). This will only increase in importance as the experience with new and innovative techniquesincluding hybrid surgical arch-FET grafts and branched/ fenestrated endovascular therapy—continues to build.

\section{Conclusions}

The evolution in the management of patients with acute type A aortic dissection has been one driven by inertia and oscillating whims, rather than progressive change. Throughout this process, the debate over the extent of the operation both proximally and distally has recurred. With the increasing complexity of care exerting pressure on contemporary surgeons, the latest meiosis in the field has been the birth of a pure-bred subspecialist: the "thoracic aortic surgeon" (181). The logical next step to improve the management of patients with AcA-AoD appears to be strict regionalization of care. Even though most patients with an AcA-AoD would survive a 2-4 hour AirEvac transport to a regional referral center in the US, sadly most will not be transferred. The feasibility and infrastructure exist, but it is up to the payers to make this happen. Realistically, only restricting reimbursement and enforcing best practice channels of care will affect change in the future.

\section{Acknowledgements}

Funding: This work was conducted with support from a KL2 Mentored Career Development Award of the Stanford 
Clinical and Translational Science Award to Spectrum (NIH KL2 TR 001083).

\section{Footnote}

Conflicts of Interest: The authors have no conflicts of interest to declare.

\section{References}

1. Howard DP, Banerjee A, Fairhead JF, et al. Populationbased study of incidence and outcome of acute aortic dissection and premorbid risk factor control: 10-year results from the oxford vascular study. Circulation 2013;127:2031-7.

2. Clouse WD, Hallett JW Jr, Schaff HV, et al. Acute aortic dissection: Population-based incidence compared with degenerative aortic aneurysm rupture. Mayo Clin Proc 2004;79:176-80.

3. Mody PS, Wang Y, Geirsson A, et al. Trends in aortic dissection hospitalizations, interventions, and outcomes among medicare beneficiaries in the united states, 20002011. Circulation. Circ Cardiovasc Qual Outcomes 2014;7:920-8.

4. Daily PO, Trueblood HW, Stinson EB, et al. Management of acute aortic dissections. Ann Thorac Surg 1970;10:237-47.

5. Attar S, Fardin R, Ayella R, et al. Medical vs surgical treatment of acute dissecting aneurysms. Arch Surg 1971;103:568-73.

6. Pape LA, Awais M, Woznicki EM, et al. Presentation, diagnosis, and outcomes of acute aortic dissection: 17year trends from the international registry of acute aortic dissection. J Am Coll Cardiol 2015;66:350-8.

7. Debakey ME, Henly WS, Cooley DA, et al. Surgical management of dissecting aneurysms of the aorta. J Thorac Cardiovasc Surg 1965;49:130-49.

8. DeBakey ME, McCollum CH, Crawford ES, et al. Dissection and dissecting aneurysms of the aorta: Twentyyear follow-up of five hundred twenty-seven patients treated surgically. Surgery 1982;92:1118-34.

9. Dake MD, Thompson M, van Sambeek M, et al. Dissect: A new mnemonic-based approach to the categorization of aortic dissection. Eur J Vasc Endovasc Surg 2013;46:175-90.

10. Hirst AE Jr, Johns VJ Jr, Kime SW Jr. Dissecting aneurysm of the aorta: A review of 505 cases. Medicine (Baltimore) 1958;37:217-79.

11. Peacock TB. Report on cases of dissecting aneurism. Transactions of the Pathological Society of London
1863;14:87.

12. Svensson LG, Labib SB, Eisenhauer AC, et al. Intimal tear without hematoma: An important variant of aortic dissection that can elude current imaging techniques. Circulation 1999;99:1331-6.

13. Coady MA, Rizzo JA, Elefteriades JA. Pathologic variants of thoracic aortic dissections. Penetrating atherosclerotic ulcers and intramural hematomas. Cardiol Clin 1999;17:637-57.

14. Robbins RC, McManus RP, Mitchell RS, et al. Management of patients with intramural hematoma of the thoracic aorta. Circulation 1993;88:II1-10.

15. Estrera AL, Sandhu HK, Leake SS, et al. Early and late outcomes of acute type a aortic dissection with intramural hematoma. J Thorac Cardiovasc Surg 2015;149:137-42.

16. Kaji S, Akasaka T, Horibata $Y$, et al. Long-term prognosis of patients with type a aortic intramural hematoma. Circulation 2002;106:I248-52.

17. Moizumi Y, Komatsu T, Motoyoshi N, et al. Management of patients with intramural hematoma involving the ascending aorta. J Thorac Cardiovasc Surg 2002;124:918-24.

18. Song JK, Kim HS, Kang DH, et al. Different clinical features of aortic intramural hematoma versus dissection involving the ascending aorta. J Am Coll Cardiol 2001;37:1604-10.

19. Austen WG, Buckley MJ, McFarland J, et al. Therapy of dissecting aneurysms. Arch Surg 1967;95:835-42.

20. Gurin D, Bulmer JW, Derby R. Dissecting aneurysm of the aorta: diagnosis and operative relief of acute arterial obstruction due to this cause. NY State J Med 1935;35:1200-2.

21. De Bakey ME, Cooley DA, Creech O Jr. Surgical considerations of dissecting aneurysm of the aorta. Ann Surg 1955;142:586-610; discussion, 611-582.

22. Shaw RS. Acute dissecting aortic aneurysm; treatment by fenestration of the internal wall of the aneurysm. N Engl J Med 1955;253:331-3.

23. Austen WG, Desanctis RW. Surgical treatment of dissecting aneurysm of the thoracic aorta. N Engl J Med 1965;272:1314-7.

24. Cooley DA, Mahaffey DE, De Bakey ME. Total excision of the aortic arch for aneurysm. Surg Gynecol Obstet 1955;101:667-72.

25. Beckwith JR, Muller WH, Warren WD, et al. Acute dissecting aneurysm of the aorta, diagnosis and selection of patients for surgery. Trans Am Clin Climatol Assoc 1959;70:1-14.

26. Bahnson HT, Spencer FC. Excision of aneurysm of the 
ascending aorta with prosthetic replacement during cardiopulmonary bypass. Ann Surg 1960;151:879-90.

27. Hufnagel CA, Conrad PW. Dissecting aneurysms of the ascending aorta: Direct approach to repair. Surgery 1962;51:84-9.

28. Morris GC Jr, Henly WS, Debakey ME. Correction of acute dissecting aneurysm of aorta with valvular insufficiency. JAMA 1963;184:63-4.

29. Debakey ME, Henly WS, Cooley DA, et al. Surgical treatment of dissecting aneurysm of the aorta. Analysis of seventy-two cases. Circulation 1961;24:290-303.

30. Hume DM, Porter RR. Acute dissecting aortic aneurysms. Surgery 1963;53:122-54.

31. Wheat MW Jr, Palmer RF, Bartley TD, et al. Treatment of dissecting aneurysms of the aorta without surgery. J Thorac Cardiovasc Surg 1965;50:364-73.

32. Rosenberg HL, Mulder DG. Dissecting thoracic aortic aneurysms. Arch Surg 1972;105:19-23.

33. Grondin C, David PR, Goor DA, et al. Dissecting aneurysms of the thoracic aorta: A review of 52 cases with consideration of factors influencing prognosis Ann Thorac Surg 1967;4:29-37.

34. McFarland J, Willerson JT, Dinsmore RE, et al. The medical treatment of dissecting aortic aneurysms. N Engl J Med 1972;286:115-9.

35. Dalen JE, Alpert JS, Cohn LH, et al. Dissection of the thoracic aorta. Medical or surgical therapy? Am J Cardiol 1974;34:803-8.

36. Appelbaum A, Karp RB, Kirklin JW. Ascending vs descending aortic dissections. Ann Surg 1976;183:296-300.

37. Kirschner LP, Twigg HL, Conrad PW, et al. Retrograde catheter aortography in dissecting aortic aneurysms. Am J Roentgenol Radium Ther Nucl Med 1968;102:349-53.

38. Miller DC, Stinson EB, Oyer PE, et al. Operative treatment of aortic dissections. Experience with 125 patients over a sixteen-year period. J Thorac Cardiovasc Surg 1979;78:365-82.

39. Godwin JD, Herfkens RL, Skioldebrand CG, et al. Evaluation of dissections and aneurysms of the thoracic aorta by conventional and dynamic ct scanning. Radiology 1980;136:125-33.

40. Oudkerk M, Overbosch E, Dee P. Ct recognition of acute aortic dissection. AJR Am J Roentgenol 1983;141:671-6.

41. Miller DC. Surgical management of aortic dissections: Indications, perioperative management, and long-term results. In: Doroghazi RM, Slater EE, editors. Aortic dissection. New York, NY: McGraw Hill, 1983:193-243.

42. Nienaber CA, von Kodolitsch Y, Nicolas V, et al. The diagnosis of thoracic aortic dissection by noninvasive imaging procedures. N Engl J Med 1993;328:1-9.

43. Rizzo RJ, Aranki SF, Aklog L, et al. Rapid noninvasive diagnosis and surgical repair of acute ascending aortic dissection. Improved survival with less angiography. J Thorac Cardiovasc Surg 1994;108:567-74; discussion 574-5.

44. Bavaria JE, Pochettino A, Brinster DR, et al. New paradigms and improved results for the surgical treatment of acute type a dissection. Ann Surg 2001;234:336-42; discussion 342-3.

45. Jakob H, Tsagakis K, Tossios P, et al. Combining classic surgery with descending stent grafting for acute debakey type i dissection. Ann Thorac Surg 2008;86:95-101.

46. Crawford ES. The diagnosis and management of aortic dissection. JAMA 1990;264:2537-41.

47. Fann JI, Smith JA, Miller DC, et al. Surgical management of aortic dissection during a 30-year period. Circulation 1995;92:II113-21.

48. Yun KL, Miller DC. Technique of aortic valve preservation in acute type a aortic dissection. Oper Tech Cardial Thorac Surg 1996;1:68.

49. Lai DT, Miller DC, Mitchell RS, et al. Acute type a aortic dissection complicated by aortic regurgitation: Composite valve graft versus separate valve graft versus conservative valve repair. J Thorac Cardiovasc Surg 2003;126:1978-86.

50. Kallenbach K, Oelze T, Salcher R, et al. Evolving strategies for treatment of acute aortic dissection type a. Circulation 2004;110:II243-9.

51. Leshnower BG, Myung RJ, McPherson L, et al. Midterm results of david v valve-sparing aortic root replacement in acute type a aortic dissection. Ann Thorac Surg 2015;99:795-800; discussion 800-1.

52. David TE, Armstrong S, Maganti M. Hancock ii bioprosthesis for aortic valve replacement: The gold standard of bioprosthetic valves durability? Ann Thorac Surg 2010;90:775-81.

53. Une D, Ruel M, David TE. Twenty-year durability of the aortic hancock ii bioprosthesis in young patients: Is it durable enough? Eur J Cardiothorac Surg 2014;46:825-30.

54. Johnston DR, Soltesz EG, Vakil N, et al. Long-term durability of bioprosthetic aortic valves: Implications from 12,569 implants. Ann Thorac Surg 2015;99:1239-47.

55. Chiang YP, Chikwe J, Moskowitz AJ, et al. Survival and long-term outcomes following bioprosthetic vs mechanical aortic valve replacement in patients aged 50 to 69 years. JAMA 2014;312:1323-9.

56. Glaser N, Jackson V, Holzmann MJ, et al. Aortic valve 
replacement with mechanical vs. Biological prostheses in patients aged 50-69 years. Eur Heart J 2015. doi: 10.1093/ eurheartj/ehv580.

57. Suri RM, Schaff HV. Selection of aortic valve prostheses: Contemporary reappraisal of mechanical versus biologic valve substitutes. Circulation 2013;128:1372-80.

58. Nishimura RA, Otto CM, Bonow RO, et al. 2014 AHA/ ACC guideline for the management of patients with valvular heart disease: A report of the American college of cardiology/American heart association task force on practice guidelines. Circulation 2014;129:e521-643.

59. Movsowitz HD, Levine RA, Hilgenberg AD, et al. Transesophageal echocardiographic description of the mechanisms of aortic regurgitation in acute type a aortic dissection: Implications for aortic valve repair. J Am Coll Cardiol 2000;36:884-90.

60. Rylski B, Bavaria JE, Milewski RK, et al. Long-term results of neomedia sinus valsalva repair in 489 patients with type a aortic dissection. Ann Thorac Surg 2014;98:582-8; discussion 588-9.

61. Geirsson A, Bavaria JE, Swarr D, et al. Fate of the residual distal and proximal aorta after acute type a dissection repair using a contemporary surgical reconstruction algorithm. Ann Thorac Surg 2007;84:1955-64; discussion 1955-64.

62. Guilmet D, Bachet J, Goudot B, et al. Use of biological glue in acute aortic dissection. Preliminary clinical results with a new surgical technique. J Thorac Cardiovasc Surg 1979;77:516-21.

63. Bachet J, Gigou F, Laurian C, et al. Four-year clinical experience with the gelatin-resorcine-formol biological glue in acute aortic dissection. J Thorac Cardiovasc Surg 1982;83:212-7.

64. Fukunaga S, Karck M, Harringer W, et al. The use of gelatin-resorcin-formalin glue in acute aortic dissection type a. Eur J Cardiothorac Surg 1999;15:564-69; discussion 570.

65. Bachet J, Goudot B, Dreyfus GD, et al. Surgery for acute type a aortic dissection: The hopital foch experience (1977-1998). Ann Thorac Surg 1999;67:2006-9; discussion 2014-9.

66. Hata M, Shiono M, Sezai A, et al. Type a acute aortic dissection: Immediate and mid-term results of emergency aortic replacement with the aid of gelatin resorcin formalin glue. Ann Thorac Surg 2004;78:853-7; discussion 857.

67. Bingley JA, Gardner MA, Stafford EG, et al. Late complications of tissue glues in aortic surgery. Ann Thorac Surg 2000;69:1764-8.
68. Kazui T, Washiyama N, Bashar AH, et al. Role of biologic glue repair of proximal aortic dissection in the development of early and midterm redissection of the aortic root. Ann Thorac Surg 2001;72:509-14.

69. Hata H, Takano H, Matsumiya G, et al. Late complications of gelatin-resorcin-formalin glue in the repair of acute type a aortic dissection. Ann Thorac Surg 2007;83:1621-6.

70. Erasmi AW, Sievers HH, Wolschlager C. Inflammatory response after bioglue application. Ann Thorac Surg 2002;73:1025-6.

71. Ngaage DL, Edwards WD, Bell MR, et al. A cautionary note regarding long-term sequelae of biologic glue. J Thorac Cardiovasc Surg 2005;129:937-8.

72. Kouchoukos NT, Karp RB, Blackstone EH, et al. Replacement of the ascending aorta and aortic valve with a composite graft. Results in 86 patients. Ann Surg 1980;192:403-13.

73. Kidd JN, Ruel GJ Jr, Cooley DA, et al. Surgical treatment of aneurysms of the ascending aorta. Circulation 1976;54:III118-22.

74. Seybold-Epting W, Meyer J, Hallman GL, et al. Surgical treatment of acute dissecting aneurysm of the ascending aorta. J Cardiovasc Surg (Torino) 1977;18:43-8.

75. Massimo CG, Presenti LF, Marranci P, et al. Extended and total aortic resection in the surgical treatment of acute type a aortic dissection: Experience with 54 patients. Ann Thorac Surg 1988;46:420-4.

76. Halstead JC, Spielvogel D, Meier DM, et al. Composite aortic root replacement in acute type a dissection: Time to rethink the indications? Eur J Cardiothorac Surg 2005;27:626-32; discussion 632-3.

77. Amano J, Kuwano H, Yokomise H. Thoracic and cardiovascular surgery in japan during 2011: Annual report by the japanese association for thoracic surgery. Gen Thorac Cardiovasc Surg 2013;61:578-607.

78. Di Eusanio M, Trimarchi S, Peterson MD, et al. Root replacement surgery versus more conservative management during type a acute aortic dissection repair. Ann Thorac Surg 2014;98:2078-84.

79. Nishida H, Tabata M, Fukui T, et al. Surgical strategy and outcome for aortic root in patients undergoing repair of acute type a aortic dissection. Ann Thorac Surg 2016;101:1464-9.

80. Moon MR, Sundt TM 3rd, Pasque MK, et al. Does the extent of proximal or distal resection influence outcome for type a dissections? Ann Thorac Surg 2001;71:1244-9; discussion 1249-50.

81. Sabik JF, Lytle BW, Blackstone EH, et al. Long-term 
effectiveness of operations for ascending aortic dissections. J Thorac Cardiovasc Surg 2000;119:946-62.

82. Williams JB, Peterson ED, Zhao Y, et al. Contemporary results for proximal aortic replacement in north america. J Am Coll Cardiol 2012;60:1156-62.

83. Hughes GC, Zhao Y, Rankin JS, et al. Effects of institutional volumes on operative outcomes for aortic root replacement in north america. J Thorac Cardiovasc Surg 2013;145:166-70.

84. Stamou SC, Williams ML, Gunn TM, et al. Aortic root surgery in the united states: A report from the society of thoracic surgeons database. J Thorac Cardiovasc Surg 2015;149:116-22.e4.

85. Wang Z, Greason KL, Pochettino A, et al. Long-term outcomes of survival and freedom from reoperation on the aortic root or valve after surgery for acute ascending aorta dissection. J Thorac Cardiovasc Surg 2014;148:2117-22.

86. Rylski B, Bavaria JE, Beyersdorf F, et al. Type a aortic dissection in marfan syndrome: Extent of initial surgery determines long-term outcome. Circulation 2014;129:1381-6.

87. David TE, Feindel CM. An aortic valve-sparing operation for patients with aortic incompetence and aneurysm of the ascending aorta. J Thorac Cardiovasc Surg 1992;103:61721; discussion 622.

88. David TE, David CM, Manlhiot C, et al. Outcomes of aortic valve-sparing operations in marfan syndrome. J Am Coll Cardiol 2015;66:1445-53.

89. Yacoub MH, Gehle P, Chandrasekaran V, et al. Late results of a valve-preserving operation in patients with aneurysms of the ascending aorta and root. J Thorac Cardiovasc Surg 1998;115:1080-90.

90. Cameron DE, Alejo DE, Patel ND, et al. Aortic root replacement in 372 marfan patients: Evolution of operative repair over 30 years. Ann Thorac Surg 2009;87:1344-9; discussion 1349-50.

91. Kvitting JP, Kari FA, Fischbein MP, et al. David valvesparing aortic root replacement: Equivalent midterm outcome for different valve types with or without connective tissue disorder. J Thorac Cardiovasc Surg 2013;145:117-26, 127.e1-5; discussion 126-7.

92. Kari FA, Liang DH, Kvitting JP, et al. Tirone david valve-sparing aortic root replacement and cusp repair for bicuspid aortic valve disease. J Thorac Cardiovasc Surg 2013;145:S35-40.e1-2.

93. David TE, Feindel CM, David CM, et al. A quarter of a century of experience with aortic valve-sparing operations. J Thorac Cardiovasc Surg 2014;148:872-9; discussion 879-80.

94. Miller DC. Rationale and results of the stanford modification of the david $\mathrm{v}$ reimplantation technique for valve-sparing aortic root replacement. J Thorac Cardiovasc Surg 2015;149:112-4.

95. Coselli JS, Volguina IV, LeMaire SA, et al. Early and 1-year outcomes of aortic root surgery in patients with marfan syndrome: A prospective, multicenter, comparative study. J Thorac Cardiovasc Surg 2014;147:1758-66, 1767.e1-4.

96. Miller DC. Valve-sparing aortic root replacement in patients with the marfan syndrome. J Thorac Cardiovasc Surg 2003;125:773-8.

97. Leyh RG, Fischer S, Kallenbach K, et al. High failure rate after valve-sparing aortic root replacement using the "remodeling technique" in acute type a aortic dissection. Circulation 2002;106:I229-33.

98. Subramanian S, Leontyev S, Borger MA, et al. Valvesparing root reconstruction does not compromise survival in acute type a aortic dissection. Ann Thorac Surg 2012;94:1230-4.

99. Miyahara S, Matsueda T, Izawa N, et al. Mid-term results of valve-sparing aortic root replacement in patients with expanded indications. Ann Thorac Surg 2015;100:845-51; discussion 852 .

100. Cabrol C, Pavie A, Gandjbakhch I, et al. Complete replacement of the ascending aorta with reimplantation of the coronary arteries: New surgical approach. J Thorac Cardiovasc Surg 1981;81:309-15.

101.Zubiate P, Kay JH. Surgical treatment of aneurysm of the ascending aorta with aortic insufficiency and marked displacement of the coronary ostia. J Thorac Cardiovasc Surg 1976;71:415-21.

102. Knight J, Baumuller S, Kurtcuoglu V, et al. Long-term follow-up, computed tomography, and computational fluid dynamics of the cabrol procedure. J Thorac Cardiovasc Surg 2010;139:1602-8.

103. Gelsomino S, Frassani R, Da Col P, et al. A long-term experience with the cabrol root replacement technique for the management of ascending aortic aneurysms and dissections. Ann Thorac Surg 2003;75:126-31.

104. Van Arsdell GS, David TE, Butany J. Autopsies in acute type a aortic dissection. Surgical implications. Circulation 1998;98:II299-302; discussion II302-4.

105. Crawford ES, Kirklin JW, Naftel DC, et al. Surgery for acute dissection of ascending aorta. Should the arch be included? J Thorac Cardiovasc Surg 1992;104:46-59.

106. Debakey ME, Henly WS, Cooley DA, et al. Aneurysms of the aortic arch: Factors influencing operative risk. Surg 
Clin North Am 1962;42:1543-54.

107. Griepp RB, Stinson EB, Hollingsworth JF, et al. Prosthetic replacement of the aortic arch. J Thorac Cardiovasc Surg 1975;70:1051-63.

108. Ott DA, Frazier OH, Cooley DA. Resection of the aortic arch using deep hypothermia and temporary circulatory arrest. Circulation 1978;58:I227-31.

109. Cooley DA, Livesay JJ. Technique of "open" distal anastomosis for ascending and transverse arch resection. Cardiovasc Dis 1981;8:421-6.

110. David TE, Armstrong S, Ivanov J, et al. Surgery for acute type a aortic dissection. Ann Thorac Surg 1999;67:19992001; discussion 2014-9.

111. Nguyen B, Muller M, Kipfer B, et al. Different techniques of distal aortic repair in acute type a dissection: Impact on late aortic morphology and reoperation. Eur J Cardiothorac Surg 1999;15:496-500; discussion 500-1.

112.Pugliese P, Pessotto R, Santini F, et al. Risk of late reoperations in patients with acute type a aortic dissection: Impact of a more radical surgical approach. Eur J Cardiothorac Surg 1998;13:576-80; discussion 580-1.

113.Lai DT, Robbins RC, Mitchell RS, et al. Does profound hypothermic circulatory arrest improve survival in patients with acute type a aortic dissection? Circulation 2002;106:I2 18-28.

114. Bachet J, Teodori G, Goudot B, et al. Replacement of the transverse aortic arch during emergency operations for type a acute aortic dissection. Report of 26 cases. J Thorac Cardiovasc Surg 1988;96:878-86.

115. Yun KL, Glower DD, Miller DC, et al. Aortic dissection resulting from tear of transverse arch: Is concomitant arch repair warranted? J Thorac Cardiovasc Surg 1991;102:35568; discussion 368-70.

116. Kazui T, Inoue N, Komatsu S. Surgical treatment of aneurysms of the transverse aortic arch. J Cardiovasc Surg (Torino) 1989;30:402-6.

117.Kazui T, Inoue N, Yamada O, et al. Selective cerebral perfusion during operation for aneurysms of the aortic arch: A reassessment. Ann Thorac Surg 1992;53:109-14.

118. Sabik JF, Lytle BW, McCarthy PM, et al. Axillary artery: An alternative site of arterial cannulation for patients with extensive aortic and peripheral vascular disease. J Thorac Cardiovasc Surg 1995;109:885-90; discussion 890-1.

119. Baribeau YR, Westbrook BM, Charlesworth DC, et al. Arterial inflow via an axillary artery graft for the severely atheromatous aorta. Ann Thorac Surg 1998;66:33-7.

120.Etz CD, von Aspern K, da Rocha ES, et al. Impact of perfusion strategy on outcome after repair for acute type a aortic dissection. Ann Thorac Surg 2014;97:78-85.

121. Comas GM, Leshnower BG, Halkos ME, et al. Acute type a dissection: Impact of antegrade cerebral perfusion under moderate hypothermia. Ann Thorac Surg 2013;96:2135-41.

122. Ueda Y, Miki S, Kusuhara K, et al. Surgical treatment of aneurysm or dissection involving the ascending aorta and aortic arch, utilizing circulatory arrest and retrograde cerebral perfusion. J Cardiovasc Surg (Torino) 1990;31:553-8.

123. Safi HJ, Brien HW, Winter JN, et al. Brain protection via cerebral retrograde perfusion during aortic arch aneurysm repair. Ann Thorac Surg 1993;56:270-6.

124. Svensson LG, Blackstone EH, Rajeswaran J, et al. Does the arterial cannulation site for circulatory arrest influence stroke risk? Ann Thorac Surg 2004;78:1274-84; discussion 1274-84.

125. de Brux JL, Subayi JB, Pegis JD, et al. Retrograde cerebral perfusion: Anatomic study of the distribution of blood to the brain. Ann Thorac Surg 1995;60:1294-8.

126. Boeckxstaens CJ, Flameng WJ. Retrograde cerebral perfusion does not perfuse the brain in nonhuman primates. Ann Thorac Surg 1995;60:319-27; discussion 327-8.

127.Juvonen T, Weisz DJ, Wolfe D, et al. Can retrograde perfusion mitigate cerebral injury after particulate embolization? A study in a chronic porcine model. J Thorac Cardiovasc Surg 1998;115:1142-59.

128. Ehrlich MP, Hagl C, McCullough JN, et al. Retrograde cerebral perfusion provides negligible flow through brain capillaries in the pig. J Thorac Cardiovasc Surg 2001;122:331-8.

129. Svensson LG, Blackstone EH, Apperson-Hansen C, et al. Implications from neurologic assessment of brain protection for total arch replacement from a randomized trial. J Thorac Cardiovasc Surg 2015;150:1140-7.e11.

130.Fusco DS, Shaw RK, Tranquilli M, et al. Femoral cannulation is safe for type a dissection repair. Ann Thorac Surg 2004;78:1285-9; discussion 1285-9.

131. Ayyash B, Tranquilli M, Elefteriades JA. Femoral artery cannulation for thoracic aortic surgery: Safe under transesophageal echocardiographic control. J Thorac Cardiovasc Surg 2011;142:1478-81.

132.Ziganshin BA, Rajbanshi BG, Tranquilli M, et al. Straight deep hypothermic circulatory arrest for cerebral protection during aortic arch surgery: Safe and effective. J Thorac Cardiovasc Surg 2014;148:888-98; discussion 898-900.

133. Usui A, Hotta T, Hiroura M, et al. Retrograde cerebral perfusion through a superior vena caval cannula protects 
the brain. Ann Thorac Surg 1992;53:47-53.

134. Shimokawa T, Takanashi S, Ozawa N, et al. Management of intraoperative malperfusion syndrome using femoral artery cannulation for repair of acute type a aortic dissection. Ann Thorac Surg 2008;85:1619-24.

135. Lawton JS, Liu J, Kulshrestha K, et al. The impact of surgical strategy on survival after repair of type a aortic dissection. J Thorac Cardiovasc Surg 2015;150:294-301.e1.

136.Immer FF, Aydin NB, Lutolf M, et al. Does aortic crossclamping during the cooling phase affect the early clinical outcome of acute type a aortic dissection? J Thorac Cardiovasc Surg 2008;136:1536-40.

137. Benedetto U, Raja SG, Amrani M, et al. The impact of arterial cannulation strategy on operative outcomes in aortic surgery: Evidence from a comprehensive metaanalysis of comparative studies on 4476 patients. J Thorac Cardiovasc Surg 2014;148:2936-43.e1-4.

138. Minatoya K, Karck M, Szpakowski E, et al. Ascending aortic cannulation for stanford type a acute aortic dissection: Another option. J Thorac Cardiovasc Surg 2003;125:952-3.

139. Reece TB, Tribble CG, Smith RL, et al. Central cannulation is safe in acute aortic dissection repair. J Thorac Cardiovasc Surg 2007;133:428-34.

140. Frederick JR, Yang E, Trubelja A, et al. Ascending aortic cannulation in acute type a dissection repair. Ann Thorac Surg 2013;95:1808-11.

141. Trinkle JK, Bryant LR. Mechanical support of the circulation: A new approach. Arch Surg 1970;101:740-3.

142. Wada S, Yamamoto S, Honda J, et al. Transapical aortic cannulation for cardiopulmonary bypass in type a aortic dissection operations. J Thorac Cardiovasc Surg 2006;132:369-72.

143. Wada J, Komatsu S, Nakae S, et al. A new cannulation method for isolated mitral valve surgery--"apicoaortic-pa" cannulation. Thoraxchir Vask Chir 1976;24:204-12.

144.Ando M, Nakajima N, Adachi S, et al. Simultaneous graft replacement of the ascending aorta and total aortic arch for type a aortic dissection. Ann Thorac Surg 1994;57:669-76.

145. Kazui T, Kimura N, Yamada O, et al. Total arch graft replacement in patients with acute type a aortic dissection. Ann Thorac Surg 1994;58:1462-8.

146. Kazui T, Washiyama N, Muhammad BA, et al. Extended total arch replacement for acute type a aortic dissection: Experience with seventy patients. J Thorac Cardiovasc Surg 2000;119:558-65.

147. Trivedi D, Navid F, Balzer JR, et al. Aggressive aortic arch and carotid replacement strategy for type a aortic dissection improves neurologic outcomes. Ann Thorac Surg 2016;101:896-905.

148. Kim JB, Chung CH, Moon DH, et al. Total arch repair versus hemiarch repair in the management of acute debakey type i aortic dissection. Eur J Cardiothorac Surg 2011;40:881-7.

149. Di Eusanio M, Berretta P, Cefarelli M, et al. Total arch replacement versus more conservative management in type a acute aortic dissection. Ann Thorac Surg 2015;100:88-94.

150. Kato M, Ohnishi K, Kaneko M, et al. New graft-implanting method for thoracic aortic aneurysm or dissection with a stented graft. Circulation 1996;94:II188-93.

151. Kato M, Kuratani T, Kaneko M, et al. The results of total arch graft implantation with open stent-graft placement for type a aortic dissection. J Thorac Cardiovasc Surg 2002;124:531-40.

152. Uchida N, Ishihara H, Shibamura H, et al. Midterm results of extensive primary repair of the thoracic aorta by means of total arch replacement with open stent graft placement for an acute type a aortic dissection. J Thorac Cardiovasc Surg 2006;131:862-7.

153.Sun L, Qi R, Zhu J, et al. Total arch replacement combined with stented elephant trunk implantation: A new "standard" therapy for type a dissection involving repair of the aortic arch? Circulation 2011;123:971-8.

154.Sun L, Qi R, Zhu J, et al. Repair of acute type a dissection: Our experiences and results. Ann Thorac Surg 2011;91:1147-52.

155. Pochettino A, Brinkman WT, Moeller P, et al. Antegrade thoracic stent grafting during repair of acute debakey $i$ dissection prevents development of thoracoabdominal aortic aneurysms. Ann Thorac Surg 2009;88:482-9; discussion 489-90.

156. Di Eusanio M, Castrovinci S, Tian DH, et al. Antegrade stenting of the descending thoracic aorta during debakey type 1 acute aortic dissection repair. Eur J Cardiothorac Surg 2014;45:967-75.

157.Itoh A, Fischbein M, Arata K, et al. "Peninsula-style" transverse aortic arch replacement in patients with bicuspid aortic valve. Ann Thorac Surg 2010;90:1369-71.

158. Omura A, Miyahara S, Yamanaka K, et al. Early and late outcomes of repaired acute debakey type i aortic dissection after graft replacement. J Thorac Cardiovasc Surg 2016;151:341-8.

159. Andersen ND, Ganapathi AM, Hanna JM, et al. Outcomes of acute type a dissection repair before and after implementation of a multidisciplinary thoracic aortic 
surgery program. J Am Coll Cardiol 2014;63:1796-803.

160. Fann JI, Sarris GE, Mitchell RS, et al. Treatment of patients with aortic dissection presenting with peripheral vascular complications. Ann Surg 1990;212:705-13.

161. Cambria RP, Brewster DC, Gertler J, et al. Vascular complications associated with spontaneous aortic dissection. J Vasc Surg 1988;7:199-209.

162. Girdauskas E, Kuntze T, Borger MA, et al. Surgical risk of preoperative malperfusion in acute type a aortic dissection. J Thorac Cardiovasc Surg 2009;138:1363-9.

163. Patel HJ, Williams DM, Dasika NL, et al. Operative delay for peripheral malperfusion syndrome in acute type a aortic dissection: A long-term analysis. J Thorac Cardiovasc Surg 2008;135:1288-95; discussion 1295-6.

164. Fann JI, Sarris GE, Miller DC, et al. Surgical management of acute aortic dissection complicated by stroke. Circulation 1989;80:I257-63.

165. Tsukube T, Hayashi T, Kawahira T, et al. Neurological outcomes after immediate aortic repair for acute type a aortic dissection complicated by coma. Circulation 2011;124:S163-7.

166. Estrera AL, Garami Z, Miller CC, et al. Acute type a aortic dissection complicated by stroke: Can immediate repair be performed safely? J Thorac Cardiovasc Surg 2006;132:1404-8.

167. Bossone E, Corteville DC, Harris KM, et al. Stroke and outcomes in patients with acute type a aortic dissection. Circulation 2013;128:S175-9.

168. Ergin MA, Galla JD, Lansman S, et al. Acute dissections of the aorta. Current surgical treatment. Surg Clin North Am 1985;65:721-41.

169. Miller DC, Mitchell RS, Oyer PE, et al. Independent determinants of operative mortality for patients with aortic dissections. Circulation 1984;70:I153-64.

170. Deeb GM, Williams DM, Bolling SF, et al. Surgical delay for acute type a dissection with malperfusion. Ann Thorac Surg 1997;64:1669-75; discussion 1675-7.

171. Rylski B, Hoffmann I, Beyersdorf F, et al. Acute aortic dissection type a: Age-related management and outcomes reported in the german registry for acute aortic dissection type a (geraada) of over 2000 patients. Ann Surg 2014;259:598-604.

172.Neri E, Toscano T, Massetti M, et al. Operation for acute type a aortic dissection in octogenarians: Is it justified? J Thorac Cardiovasc Surg 2001;121:259-67.

173.McKneally MF. "We don't do that here": Reflections on the siena experience with dissecting aneurysms of the thoracic aorta in octogenarians. J Thorac Cardiovasc Surg 2001;121:202-3.

174. Hata M, Sezai A, Niino T, et al. Should emergency surgical intervention be performed for an octogenarian with type a acute aortic dissection? J Thorac Cardiovasc Surg 2008;135:1042-6.

175. Trimarchi S, Eagle KA, Nienaber CA, et al. Role of age in acute type a aortic dissection outcome: Report from the international registry of acute aortic dissection (irad). J Thorac Cardiovasc Surg 2010;140:784-9.

176. Roselli EE, Idrees J, Greenberg RK, et al. Endovascular stent grafting for ascending aorta repair in high-risk patients. J Thorac Cardiovasc Surg 2015;149:144-51.

177. Vallabhajosyula P, Gottret JP, Bavaria JE, et al. Endovascular repair of the ascending aorta in patients at high risk for open repair. J Thorac Cardiovasc Surg 2015;149:S144-50.

178. Knipp BS, Deeb GM, Prager RL, et al. A contemporary analysis of outcomes for operative repair of type a aortic dissection in the united states. Surgery 2007;142:524-8; discussion 528.e1.

179. Chikwe J, Cavallaro P, Itagaki S, et al. National outcomes in acute aortic dissection: Influence of surgeon and institutional volume on operative mortality. Ann Thorac Surg 2013;95:1563-9.

180. Peterson MD, Mazine A, El-Hamamsy I, et al. Knowledge, attitudes, and practice preferences of canadian cardiac surgeons toward the management of acute type a aortic dissection. J Thorac Cardiovasc Surg 2015;150:824-31.e1-5.

181. Miller DC. Another meiosis in the specialty of cardiovascular and thoracic surgery: Birth of the purebred "thoracic aortic surgeon"? J Am Coll Cardiol 2014;63:1804-6.
Cite this article as: Chiu P, Miller DC. Evolution of surgical therapy for Stanford acute type A aortic dissection. Ann Cardiothorac Surg 2016;5(4):275-295. doi: 10.21037/ acs.2016.05.05 